\title{
Preoperative ultrasonography in the evaluation of abdominal wall adhesions
}

\author{
Neha Rani ${ }^{1}$, Shalini Rajaram ${ }^{1}$, Sarita Chaube $^{2 *}$, Vineeta Rathi ${ }^{1}$
}

\begin{abstract}
${ }^{1}$ Department of Obstetrics and Gynecology, University College of Medical Sciences and Guru Teg Bahadur Hospital, Delhi, India

${ }^{2}$ Department of Obstetrics and Gynecology, SGT Medical College and Hospital, SGT University, Gurugram, Haryana, India
\end{abstract}

Received: 19 August 2020

Accepted: 29 September 2020

\section{*Correspondence:}

Dr. Sarita Chaube,

E-mail: saritachaube@gmail.com

Copyright: (C) the author(s), publisher and licensee Medip Academy. This is an open-access article distributed under the terms of the Creative Commons Attribution Non-Commercial License, which permits unrestricted non-commercial use, distribution, and reproduction in any medium, provided the original work is properly cited.

\section{ABSTRACT}

Background: To detect and document preoperatively the presence of bowel and omental adhesions in the periumbilical region and along the previous abdominal scar using visceral slide scale by ultrasonography, and to compare the ultrasonic findings with intraoperative laparotomy or laparoscopy.

Methods: It was a cross-sectional observational study conducted between for 18 months at Guru Teg Bahadur Hospital, Delhi. Patients who had previously undergone abdominal surgery and were subsequently admitted for either laparotomy or laparoscopy $(\mathrm{N}=100)$ were selected. All patients underwent ultrasonography for visceral slide evaluation both along the scar and in a radius of $4 \mathrm{~cm}$ around the umbilicus. Later, peroperative findings were compared with ultrasonic findings.

Results: Mean visceral slide without and with adhesions was $2.39( \pm 1.21)$ versus $1.74( \pm 1.26) \mathrm{cm}$, correlation being significant $(\mathrm{p}=0.017)$ along the scar. While, the mean slide along the scar without and with adhesions in periumbilical region was $2.33( \pm 1.24)$ versus $1.07( \pm 1.07) \mathrm{cm},(\mathrm{p}=0.007)$ on un-paired t-test showing sensitivity=51.6\%, specificity $=81.15 \%$, positive predictive value $=55.2 \%$, and negative predictive value $=78.9 \%$. Patients with bowel adhesions $(\mathrm{N}=3)$ had restricted visceral slide both in periumblical region and along the scar $(1.07$ and $0.5 \mathrm{~cm}$ respectively).

Conclusions: Preoperative ultrasonography using visceral slide is a valuable technique in the detection of abdominal wall adhesions. A slide of $\leq 1 \mathrm{~cm}$ in the periumbilical region strongly suggests bowel adhesions.

Keywords: Abdominal wall, Adhesions, Ultrasonography, Abdominal scar, Visceral slide

\section{INTRODUCTION}

The ability to perform surgery is one of the greatest achievements of medicine. However, what has largely been overlooked is an unwanted natural consequence of surgery - adhesions or soft tissue attachments. Adhesive disease represents a significant cause of operative morbidity.

Formation of adhesions is a physiologic consequence of peritoneal tissue repair after laparotomy and laparoscopic procedures. After the initial injury, mesothelial cells secrete fibrinous exudates to cover the defect, which later induces fibroblast migration and proliferation, collagen deposition, and ultimately fibrous adhesion formation and neovascularisation. ${ }^{1}$

Whenever prior laparotomy has been performed, the laparoscopist must be mindful of using Verres needle and trocar insertion, because abdominal anatomy may be altered. ${ }^{2}$ In some cases, injury inevitably occurs due to the adherent omentum in the form of lacerations, hematoma, 
bleeding or direct injury of the bowel which may be adherent to the previous abdominal scar. ${ }^{3}$

It is estimated that $27 \%$ of the patients develop adhesions to the omentum and bowel following surgery by Pfannensteil incision, 55\% develop adhesions in the midline vertical incision below umbilicus, and $67 \%$ develop adhesions in the midline vertical incisions above umbilicus. $^{2}$

Incidence of subumbilical bowel adhesions and subsequent bowel injury is more closely related to the indication for previous laparotomy than the type and number of previous laparotomies. ${ }^{2}$ Severe adhesions are associated with previous adhesions, generalized peritonitis, bowel resection after bowel obstruction, oncologic procedures with omentectomy, previous radiation, and intraperitoneal chemotherapy. ${ }^{2}$

Establishing a preoperative diagnosis of adhesions is difficult. Although laparoscopy remains the gold standard in the diagnosis of adhesions, ultrasound has been evaluated as non-invasive diagnostic technique. Zinther et al in their first comparative study showed no significant difference in detection of abdominal wall adhesions on transabdominal ultrasonography (USG) and cine magnetic resonance imaging (MRI), though USG was superior in detecting adhesion free zones. ${ }^{4}$ Ultrasound has been used to locate abdominal wall adhesions in patients with previous surgeries to aid in the safe placement of the initial laparoscopic access. The underlying principle is to scan for spontaneous visceral slide caused by respiratory excursions of the diaphragm, as well as visceral slide induced by manual pressure. Using this technique in the assessment of an existing abdominal scar, the periumbilical region, and the remaining abdominal quadrants, Caprini and colleagues were able to ultrasonographically identify all abdominal wall adhesions present in 30 patients undergoing laparoscopy following prior laparotomy. ${ }^{5}$ Similar encouraging results have been found in a number of other studies.

\section{METHODS}

This study presents the evidence based work on postoperative adhesion formation and strategies to diagnose abdominal wall adhesions preoperatively and prevent inadvertent injuries during abdominal entry.

The study was a prospective, cross-sectional observational study conducted over a period of 18 months, at Department of Obstetrics and Gynecology and Department of Radiodiagnosis, University College of Medical Sciences and Guru Teg Bahadur Hospital, Delhi.

The study was conducted on 100 patients who had previously undergone abdominal surgery and were posted for laparoscopy or laparotomy following the fulfillment of criteria which included previous history of cesarean section, hysterectomy, laparotomy for tubo-ovarian masses, ectopic pregnancy and sling operations. Those who had undergone previous diagnostic or operative laparoscopy or who had undergone intestinal surgery e.g. intestine or colon surgery, were included. Such patients were selected, irrespective of the number of surgeries they have already undergone, and the type of scar.

Patients with suspected abdominal tuberculosis, frozen pelvis, history of appendicectomy, cholecystectomy, nephrectomy, those with acute or chronic pelvic inflammatory disease and those who had received abdominal or pelvic radiotherapy for treatment of genital or gastrointestinal malignancies were excluded. A detailed history including obstetric, menstrual, past history of previous surgery was any other associated diseases was taken and thorough clinical examination including examination for assessment of scar- its type, length, type of healing and presence of fibrosis or keloid, along with necessary investigations were carried out.

Subsequently, USG for visceral slide evaluation was carried out 2-3 days prior to day of surgery. Every patient selected was advised to remain fasting overnight and to empty her bladder before the procedure and was performed by a radiologist. The ultrasound examination was performed with the patient in supine position. Abdominal USG was carried out using 5-12 $\mathrm{mHz}$ frequency linear probe on a real time 2 dimensional (2D) ultrasound Philips (HDL-5000 Sono CT) machine. Acoustic coupling was achieved with the use of ultrasound gel.

Ultrasound scanning was begun by observing the junction between the abdominal wall and abdominal contents (Figure 1). The sliding of the abdominal viscera immediately deep to the abdominal wall as a result of respiratory movements was assessed. This is called the visceral slide. During the evaluation of visceral slide, patient was asked to take spontaneous respiration and visceral movements were observed. Visceral slide was assessed from the proximal edge of the bowel seen during quiet respiration and was marked with an arrow on USG screen using the initial site and from the same site after the bowel had slided following deep inspiration. If spontaneous visceral slide appeared restricted, patient was asked to take a deep breath and then longitudinal slide was noted and the result was given in centimeters (Figure 2)

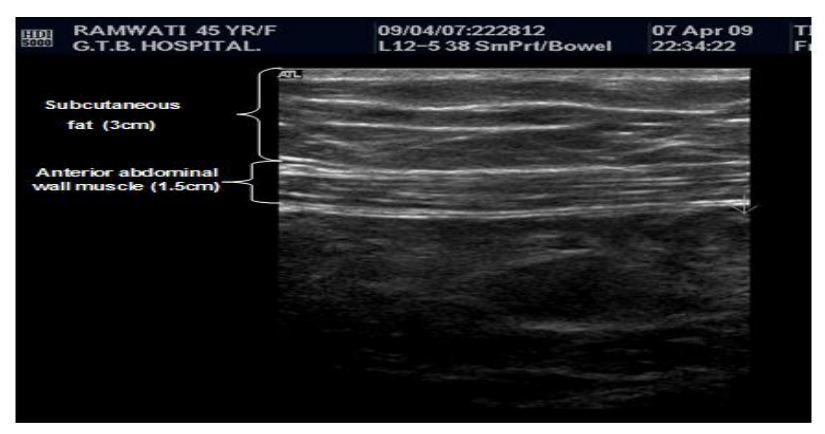

Figure 1: Scan with high frequency (5-12 mHz) linear transducer showing layers of anterior abdominal wall. 


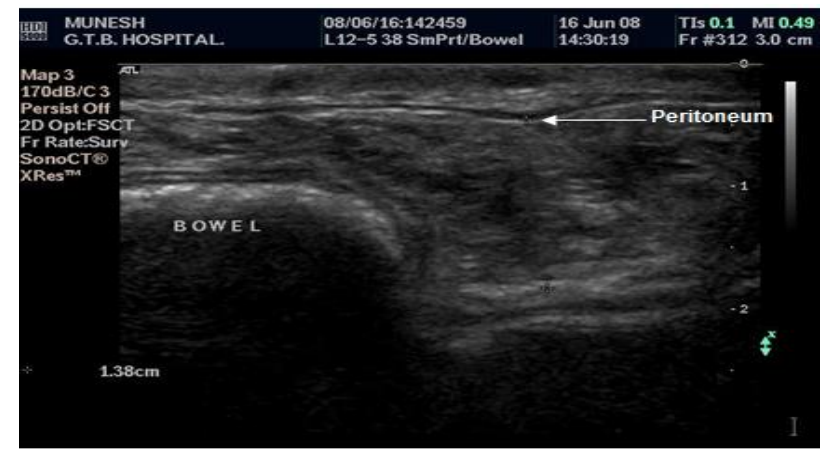

Figure 2: Scan with high frequency $(5-12 \mathrm{mHz})$ linear transducer showing layers of anterior abdominal wall with underlying bowel.

Bowel was identified either as a "target pattern" or as collection of hyperechoic shadows indicative of air in the bowel or as hypoechoic wall with internal valvulae or contents with or without peristalsis. Omentum is identified as a hypoechoic mixed density soft tissue structure not showing any peristaltic activity or air or target pattern (Figure 3).

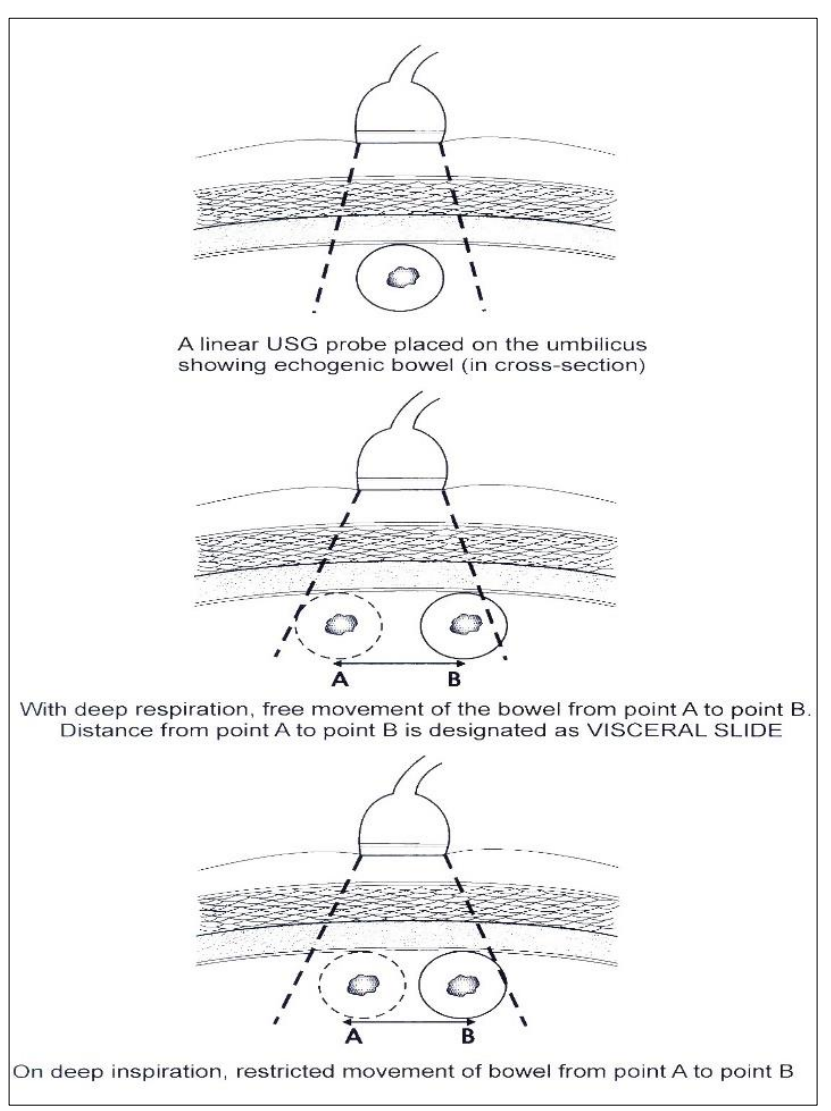

Figure 3: Pictorial representation of visceral slide.

The visceral movements were also assessed under the scar and examination was done in two or three parts depending on the length of the scar. The areas showing cluster of high and low intensity structures were focused and their excursion in the longitudinal direction was noted up to three times and an average was taken and given in centimeters. The visceral movements in centimeters were observed as described above in the periumbilical region in a radius of $4 \mathrm{~cm}$ and the slide was recorded in the upper, lower, right and left side in this region. Measurements were done manually by placing ultrasonic calipers on demarcated bowel or omentum. In case bowel or omentum adhesions were observed, the operating surgeon was informed.

On the day of surgery, after the patient was anaesthetized, the laparoscope was introduced or abdominal wall opened in case of laparotomy. Operative findings pertaining to adhesions under the umbilicus and previous incision were identified and were noted as present or absent. If present, then their types, either omental or bowel or both, flimsy, dense, vascular or not and other operative findings were noted.

Clinical data analysis was done using discriminant analysis, Fisher's exact test, Pearson's chi square test and unpaired t-test.

\section{RESULTS}

The patient characteristics like age, residence, socioeconomic status and parity, and body mass index (BMI) were evaluated. The mean age of patients was 35.6 \pm 9.18 years, majority of patients $(55 \%)$ were in the age group between 26 and 35 years. Most of the patients belonged to the upper lower group of socio-economic strata. $75 \%$ patients in the study were multiparous, $14 \%$ were nulliparous and $11 \%$ were primiparous. The mean BMI of the patients was $22.83 \pm 3.26$. 54\% patients had BMI between 20 and 25, while in $23 \%$ patients each BMI was $<20$ and $>25$ respectively.

Out of 100 patients, $76 \%$ patients in the study had surgery for gynecological indications while $25 \%$ patients had surgery for obstetric indications. Number of patients who underwent one previous surgery in the past was 86; 13 had two previous surgeries while one had history of three previous surgeries. Adhesions were found to be statistically significant in patients with more than one previous gynecological surgery $(\mathrm{p}=0.05)$ in the past while the correlation was not found to be significant in patients with more than one previous obstetric surgery $(\mathrm{p}=0.378)$ in the past (Table 1).

Table 1: Background parameters.

\begin{tabular}{|l|l|}
\hline Background parameters & $\begin{array}{l}\text { Number of } \\
\text { patients }\end{array}$ \\
\hline Age (median - 26 to 35 years) & 55 \\
\hline Socio-economic status (upper lower) & 48 \\
\hline Parity & \\
\hline Multiparous & 75 \\
\hline Nulliparous & 14 \\
\hline Primiparous & 11 \\
\hline
\end{tabular}




\begin{tabular}{|ll|}
\hline Background parameters & $\begin{array}{l}\text { Number of } \\
\text { patients }\end{array}$ \\
\hline Body mass index (mean) & 22.83 \\
\hline Surgery for & \\
\hline Gynecological indications & 76 \\
\hline Obstetrical indications & 25 \\
\hline No. of surgeries in the past & \\
\hline One & 83 \\
\hline Two & 13 \\
\hline Three & 1 \\
\hline $\begin{array}{l}\text { No. of patients with previous } \\
\text { laparotomy }\end{array}$ & 56 \\
\hline Laparoscopy & 39 \\
\hline Both laparotomy and laparoscopy & 5 \\
\hline $\begin{array}{l}\text { Average duration of postoperative } \\
\text { hospital stay (<3 days) }\end{array}$ & 50 \\
\hline Types of scar & \\
\hline Vertical scar & 43 \\
\hline Pfannensteil scar & 36 \\
\hline Single laparoscopic scar & 18 \\
\hline Multiple laparoscopic scar & 3 \\
\hline Healing & \\
\hline Primary intention & 95 \\
\hline Secondary intention & 5 \\
\hline Length of scar (cm) & 50 \\
\hline $1-5$ & 40 \\
\hline $5-10$ & 9 \\
\hline $10-15$ & 1 \\
\hline$>15$ & \\
\hline & \\
\hline
\end{tabular}

39 patients had prior history of laparoscopy, 56 patients previously had laparotomy including 25 patients who underwent cesarean section while five patients had both laparoscopy and laparotomy. 87 patients underwent laparotomy and 13 patients underwent laparoscopic surgery. 69 patients were found to have no abdominal adhesions on surgery; 26 had omental adhesions, one had only bowel and four patients had both omental and bowel adhesions.

The incidence of adhesions following laparoscopic surgery was lowest at $15.4 \%, 36.4 \%$ for laparotomy with vertical incisions and 50\% with Pfannensteil for gynecological surgery. The incidence of adhesions in obstetric surgery for Pfannensteil incision was $42.8 \%$ versus $35.3 \%$ for vertical incision. The difference in adhesions between vertical and laparoscopic and Pfannensteil and laparoscopic scars was statistically significant $(\mathrm{p}=0.015$ and $\mathrm{p}=0.025$ respectively). Patients with multiple puncture laparoscopic scars had adhesions in $66.6 \%$ versus $33.3 \%$ in single laparoscopic scars. The difference in adhesions was not statistically significant between vertical and Pfannensteil incisions ( $\mathrm{p}$ value $=0.722$ ).

A significant correlation was found between the visceral slide along the scar (mean $1.74 \pm 1.26 \mathrm{~cm}$ ) on USG and abdominal wall adhesions on surgery, $\mathrm{p}$ value $=0.017$
(Table 2). Correlation was also found to be significant between the visceral slide in the lower region of the periumbilical area (mean $2.83 \pm 1.14 \mathrm{~cm}$ ) on USG and abdominal wall adhesions on surgery, $\mathrm{p}$ value $=0.029$ (Table 3). Visceral slide in the lower region of the umbilical area with mean of $1.59( \pm 0.905) \mathrm{cm}$ was associated with periumbilical adhesions. This was statistically significant with $\mathrm{p}$ value $<0.05$. A mean slide of $1.07( \pm 1.076) \mathrm{cm}$ along the scar was associated with periumbilical adhesions with $\mathrm{p}$ value $=0.007$. More importantly, the patients with bowel adhesions $(\mathrm{N}=4)$ were associated with a restricted visceral slide both in the periumbilical region and along the scar $(1.07$ and $0.5 \mathrm{~cm}$ respectively) (Figure 4 and 5).

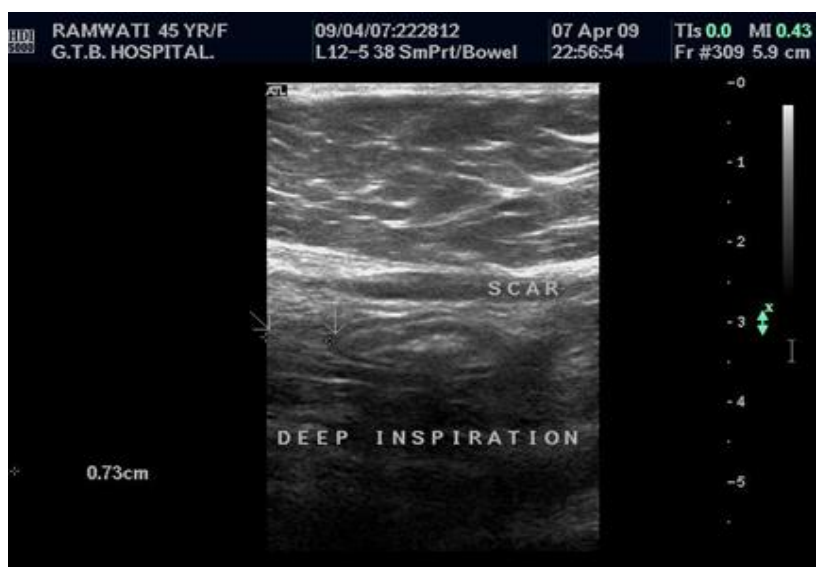

Figure 4: Target shaped bowel loop showing hypoechoic periphery and central increased echogenicity. Initial position in quiet respiration of this bowel loop marked by USG arrow ( $\downarrow$ ). Final position of the proximal edge of this target shaped bowel loop after deep inspiration marked by second arrow $(\downarrow)$. Distance between position of two arrows is marked by cursors (+) and measures $0.73 \mathrm{~cm}$.

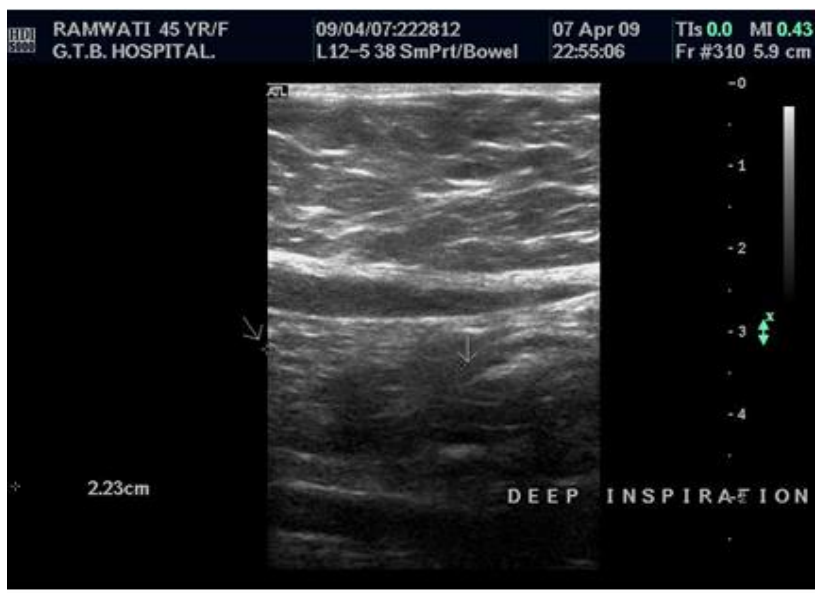

Figure 5: Visceral slide of bowel loop measured between cursors is $2.23 \mathrm{~cm}$ on deep inspiration.

Thus a slide of $\leq 1 \mathrm{~cm}$ in the periumbilical regions strongly suggested bowel adhesions. 
Table 2: Visceral slide (in $\mathrm{cm}$ ) along the scar versus abdominal wall adhesions.

\begin{tabular}{|lllll|}
\hline & No. of patients & Adhesions & Visceral slide, mean $( \pm$ SD) & P value \\
\hline USG slide - along the & 69 & Absent & $2.39 \pm 1.216$ & 0.017 \\
\cline { 2 - 5 } scar & 31 & Present & $1.74 \pm 1.268$ & \\
\hline
\end{tabular}

$\mathrm{P}$ value $=0.017$ ( significant) on unpaired $\mathrm{t}$-test

Table 3: Periumbilical region: correlation of visceral slide with abdominal wall adhesions along the scar.

\begin{tabular}{|c|c|c|c|c|}
\hline & Type of adhesions & No. of patients & Visceral slide, mean \pm SD & P value \\
\hline \multirow{2}{*}{ USG slide - upper region } & Absent & 69 & $3.12 \pm 0.94$ & \multirow{2}{*}{0.104} \\
\hline & Present & 31 & $2.78 \pm 1.014$ & \\
\hline \multirow{2}{*}{$\begin{array}{l}\text { USG slide - lower } \\
\text { Region }\end{array}$} & Absent & 69 & $2.82 \pm 1.174$ & \multirow{2}{*}{$0.029 *$} \\
\hline & Present & 31 & $2.26 \pm 1.173$ & \\
\hline \multirow{2}{*}{ USG slide - right side } & Absent & 69 & $2.99 \pm 1.086$ & \multirow{2}{*}{0.165} \\
\hline & Present & 31 & $2.67 \pm 1.007$ & \\
\hline \multirow{2}{*}{ USG slide - left side } & Absent & 69 & $2.98 \pm 1.051$ & \multirow{2}{*}{0.110} \\
\hline & Present & 31 & $2.61 \pm 1.073$ & \\
\hline
\end{tabular}

$* \mathrm{P}$ value $=0.029$ (significant)

\section{DISCUSSION}

Post-operative adhesions are a natural consequence of surgical tissue trauma and healing. ${ }^{6}$ Intra-abdominal adhesions as a result of previous abdominal surgery are predisposing factors to injury of intraabdominal organs during abdominal entry by either laparoscopy or laparotomy. ${ }^{6}$

Previous studies confirm the frequency of anterior abdominal wall adhesions to be significantly increased in women with laparotomy compared to laparoscopy. In the study by Brill et al in 1995, the adhesions to omentum and bowel were found in $27 \%$ in Pfannensteil group, $55 \%$ in the midline below umbilicus group and $67 \%$ in the midline above the umbilicus group. ${ }^{2}$ Patients with prior midline incisions of either type were more likely to have adhesions than those with prior Pfannensteil incisions $(p<0.01)$. Levrant et al in 1997, in their study described the frequency of adhesions was significantly greater in patients with midline vertical versus suprapubic transverse incision $(\mathrm{p}<0.05){ }^{7}$ In our study, the adhesions were found to be comparable in patients with Pfannensteil (44.4\%) and vertical $(39.6 \%)$ scars. The incidence of adhesions was least with laparoscopic scars $(15.4 \%)$. On analyzing the incidence of adhesions in midline vertical and Pfannensteil with laparoscopic incisions, the difference was statistically significant ( $\mathrm{p}=0.015$ and 0.025 respectively). However, the incidence of adhesions with multiple puncture laparoscopic surgery $(\mathrm{N}=2)$ was $66 \%$. The frequency of adhesions in the Pfannensteil group was more in our patients compared to Brill et al and Levrant et al. ${ }^{2,7}$

In a recent study Dhama et al witnessed comparable findings of $6.7 \%$ patients developing adhesions after laparoscopy, 56.7\% patients following Pfannensteil incision, $33.3 \%$ after midline infraumbilical incision and $3.3 \%$ after right paramedian incision. ${ }^{8}$
Patients with midline incisions performed for gynecological indications had significantly more adhesions (42.08\%) than all types of incisions performed for obstetric indications $(21.81 \%)$, as stated in the study by Brill et al. ${ }^{2}$ However in our study, adhesions in obstetric group showed an incidence of $40 \%$ versus $29 \%$ gynecological surgery group. This difference may be attributed to greater number of laparoscopic surgeries $(\mathrm{N}=39)$ in gynecological surgery group.

Study by Levrant shows $69 \%$ of the patients had midline vertical incisions for gynecological surgery while $53 \%$ had the same incision for obstetric indications. ${ }^{7} 26 \%$ patients had transverse suprapubic incision for gynecological surgery while $40 \%$ had it for obstetric surgery. $68.75 \%$ patients in our study had vertical infraumbilical incision for gynecological and $72 \%$ for obstetric surgery while $31.25 \%$ had Pfannensteil incisions for gynecological surgery and $28 \%$ for obstetric surgery. Our study shows a greater use of transverse incision for gynecological surgery versus the study by Levrant. Levrant et al used vertical incision for obstetric surgery (53\%) in fewer patients compared to our study (72\%). This difference may reflect more emergency obstetric surgeries in our patients vis-a-vis patients in Levrant's study. ${ }^{7}$

In the study by Levrant, the frequency of adhesions to anterior abdominal wall increased from $53 \%$ to $70 \%$, when comparing one incision with two or more midline incisions. In those with transverse suprapubic incision, adhesions increased from $23 \%$ to $38 \%$ when comparing one laparotomy with two or more laparotomies. ${ }^{7}$ However, statistical analysis found no significant difference $(\mathrm{p}>0.05)$ between one prior surgery or two or more for the presence of adhesions. In our study, the frequency of incisions increased from $27.3 \%$ to $70 \%$ in patients with previous one vertical incision in comparison to more than one vertical incision in the past. In the present study, the incidence of adhesions following multiple gynecologic surgery was 
$66.6 \%$ versus $25.7 \%$ following single surgery while the incidence of adhesions in patients with history of more than one cesarean section in the past was $57.2 \%$ compared to $30 \%$ in patients with prior single surgery. This difference was found to be statistically significant in patients with multiple vertical laparotomy incisions for gynecologic indications $(\mathrm{p}=0.05)$. However, the difference was not significant in more than one cesarean section $(\mathrm{p}=0.378)$.

In a study by Rafii and colleagues, patients were recruited for the study to assess the morbidity from closed laparoscopic access and the role of previous surgery on the occurrence of these complications. ${ }^{9}$ The types of incisions for the previous surgery were midline laparotomy and Pfannensteil incision in $59 \%$ cases, $37 \%$ cases had previous laparoscopies and $4.5 \%$ cases had trans-rectal incisions. $29 \%$ cases had minor complications (failure of Verres needle entry, sub peritoneal insufflation and omental emphysema) while there was only one $(0.9 \%)$ case of bowel injury, which was treated laparoscopically. No case of mortality was noted. ${ }^{9}$

In our study, out of 100 patients, 87 patients underwent laparotomy and 13 patients had laparoscopic surgery. No case of visceral or vascular complication and no case of mortality was noted. In 4 patients with bowel adhesions on USG, 3 underwent laparotomy and the surgeon was informed prior to surgery. One patient underwent laparoscopy and the Palmer's point was used for abdominal access. One patient with bowel adhesion on surgery went undetected on USG as having omental adhesions.

Audebert et al in 2000, recommended preliminary inspection of the umbilical area with a microlaparoscope and insertion of the umbilical trocar under direct vision for patients at risk for adhesions to reduce complications associated with insertion of the umbilical trocar. ${ }^{10}$ When adhesions to the periumbilical region were present, a site free of adhesions and appropriate for insertion of primary trocar was selected.

In 1991, Sigel et al were the first to describe a completely non-invasive technique for diagnosis of abdominal wall adhesions and coined the term visceral slide to describe the degree of movement of the abdominal viscera in relation to the abdominal wall. ${ }^{11}$ Thus, preoperative ultrasound examination could enhance the safety of peritoneal cavity access in patients exhibiting abdominal wall adhesions.

In the study by Sigel et al restricted visceral slide was found in $58.3 \%$ of subjects displaying healed abdominal scars from previous operations and was not detected at all in those who exhibited no history of previous surgery or peritonitis. ${ }^{11}$ Visceral slide findings corresponded in all instances to operative findings in subjects who underwent post-ultrasound abdominal operations, using a cut off of $<1 \mathrm{~cm}$ of slide to predict adhesions along the scar while in our study at a mean visceral slide of $1.74( \pm 1.26) \mathrm{cm}$, no adhesions were seen. However, when visceral slide along the scar was correlated with periumbilical adhesions, a slide of $<1.07 \mathrm{~cm}$ was found to be discriminant.

Kolecki et al in 1994, showed encouraging results with this technique and documented a sensitivity of $90 \%$, specificity of $92 \%$ and an overall accuracy of $91 \% .{ }^{12}$ It was suggested that this technique may be less accurate in the lower one third of the abdomen because the degree of visceral slide is hampered by the lack of respiratory force transmitted to this area. They noted that majority of their false ultrasound interpretations involved the lower one third of the abdomen.

In our study too, there was technical difficulty in documenting visceral slide in patients with Pfannensteil scars. We noted the mean visceral slide in patients with Pfannensteil incision was $1.81( \pm 1.17) \mathrm{cm}$ without adhesions versus $1.67( \pm 1.53) \mathrm{cm}$ in patients with adhesions.

Borzellino et al in their study assessed two ultrasonographic signs: visceral slide and the peritoneal reflection band. ${ }^{13}$ When there was rectilinear translation movement of the two observation points, the sign was considered negative; whereas when there was no movement or angular movement, the sign was considered positive regardless of the amplitude. However, no cut off (in $\mathrm{cm}$ ) for visceral slide was used and a rotational or translational movement at a fixed point was considered to have adhesions. However, in our study we could not reproduce these findings.

Aubé et al evaluated this technique in a multicenter trial incorporating 8 centers used the same criteria for adhesion detection as described by Sigel et al i.e. amplitude of intraperitoneal organ movements of $<1 \mathrm{~cm} .{ }^{11,14}$ The study showed a sensitivity of $79 \%$, specificity of $75 \%$ and accuracy of $76 \%$. They speculated that the results might have been affected by the fact that majority of their patients were overweight, with a mean BMI of 28 . They also stated that omental adhesions were barely detectable by the radiologist and as a result were not included in the final analysis. Our study shows sensitivity of $51.6 \%$, specificity of $81.15 \%$, positive predictive value (PPV) of $55.2 \%$ and negative predictive value (NPV) of $78.9 \%$ using visceral slide technique.

Kothari and associates in their study on accuracy of transabdominal ultrasound in identifying intra-abdominal adhesions categorized the intended bowel sites to have free movement (no adhesions), chaotic movements (omental adhesions) or no movements (frozen bowel) showed the sensitivity of frozen bowel of $77.8 \%$ with a specificity of $97.9 \% .15$ The sensitivity of finding omental adhesions was $42.5 \%$ and specificity was $89.9 \%$. However, these authors mapped adhesions at 6 sites in the upper abdomen for placement of trocars for laparoscopic Roux-en-Y gastric bypass and cannot be compared to the present study. 
Larciprete et al in order to promote safer laparoscopy procedures studied on visceral slide sign ultrasonographically, besides evaluating abdominal wall thickness and urachus to peritoneum (UTP) thickness. ${ }^{16}$ While visceral slide is determined as a method to detect abdominal wall adhesions, UTP thickness as a measure requires further research.

Nezhat et al in 2014, found visceral slide test on ultrasonography as a simple and reliable test for detecting periumbilical adhesions in outpatient department (OPD) settings compared to preoperative USG test for visceral slide and periumbilical USG guided saline infusion test. ${ }^{17}$ For the study group, the office visceral slide test had a sensitivity of $83.3 \%$, specificity of $100 \%$, PPV of $100 \%$, NPV of $98.5 \%$, and diagnostic accuracy of $98.6 \%$. The preoperative examination with visceral slide test had a sensitivity of $83.3 \%$, specificity of $96.8 \%$, PPV of $71.4 \%$, NPV of $98.4 \%$, and diagnostic accuracy of $95.7 \%$. The periumbilical ultrasound-guided saline infusion test had a sensitivity of $66.7 \%$, specificity of $98.4 \%$, PPV of $80 \%$, NPV of $96.9 \%$, and diagnostic accuracy of $95.7 \%$. Although the sensitivities for all the three tests are high, the $95 \%$ confidence intervals are wide because of the low incidence of periumbilical adhesions and small study population. ${ }^{17}$

On similar pattern as Siegel et al and Aube et al recently, Firoozabadia and associates evaluated 47 subjects for adhesions by spontaneous and induced visceral slide by deep breathing. ${ }^{11,14,18} 36 \%$ patients were without any adhesions, $25 \%$ with thin adhesions and the rest with thick adhesions. The value of spontaneous visceral slide (SVS) was $10.07 \mathrm{~mm}$ and induced visceral slide (IVS) was 46.38 $\mathrm{mm}$. $60 \%$ subjects had SVS $<1 \mathrm{~cm}$ and for the same IVS was $<1 \mathrm{~cm}$. The sensitivity of the procedure was $83.3 \%$ and the specificity was $51.7 \%$.

\section{CONCLUSION}

Our study on 100 patients with prior history of laparotomy (vertical infraumbilical or Pfannensteil) and laparoscopic surgery planned for subsequent laparoscopy/laparotomy underwent USG for evaluation of anterior abdominal wall adhesions (omental or bowel or both) through visceral slide technique. A significant correlation was found between the visceral slide along the scar and in the lower region of periumbilical area on ultrasonography and abdominal wall adhesions on surgery. A remarkable number of studies have concluded that transabdominal ultrasound identifies intraabdominal adhesions prior to laparoscopy. Widespread application of this totally noninvasive technique may decrease trocar related injuries during laparoscopic procedures in patients with previous abdominal surgery. Measuring visceral slide improves preoperative prediction of both presence and absence of bowel adhesions in patients with previous abdominal operations or infections. Therefore, ultrasound may improve the safety margins of initial laparoscopic port placement and avoid iatrogenic bowel injury during laparotomy and laparoscopy.

Funding: No funding sources

Conflict of interest: None declared

Ethical approval: The study was approved by the Institutional Ethics Committee

\section{REFERENCES}

1. Nehzat C, Berker B. Laparoscopic adhesiolysis and adhesion prevention. Nehzat C, Nehzat F (eds.) In: Nezhat's Operative Gynecologic Laparoscopy and Hysteroscopy. 3rd ed. Cambridge. Cambridge University Press. 2008;304-15.

2. Brill AI, Nezhat F, Nezhat $\mathrm{CH}$, Nezhat C. The incidence of adhesions after prior laparotomy: A laparoscopic appraisal. Obstet Gynecol. 1995;85:26972.

3. Krebs HB. Intestinal injury in gynaecologic surgery: A ten-year experience. Am J Obstet Gynecol. 1986;155:509-14.

4. Zinther NB, Zeuten A, Marinovskij E, Haislund M. Detection of abdominal wall adhesions using visceral slide. Surg Endosc. 2010;24:1361-6.

5. Caprini JA, Arcelus JA, Swanson J, Coats R, Hoffman $\mathrm{K}$, Brosnan JJ, et al. The ultrasonic localisation of abdominal wall adhesions. Surg Endosc. 1995;9:2835.

6. The Practice Committee of the American Society for Reproductive Medicine in collaboration with the Society of Reproductive Surgeons. Pathogenesis, consequences, and control of peritoneal adhesions in gynaecologic surgery. Fertil Steril. 2008;90(3):144-9.

7. Levrant SG, Bieber EJ, Barnes RB. Anterior Abdominal Wall Adhesions after Laparotomy or Laparoscopy. J Am Assoc Gynecol Laparosc. 1997;4(3):353-6.

8. Dhama V, Dhama V, Chaudhary R, Singh S, Aafrin $\mathrm{S}$. Role of ultrasound in reducing complication during primary trocar insertion in laparoscopic surgery: prospective observational study. Int J Reprod Contracept Obstet Gynecol. 2018;7(7):2747-52.

9. Rafii A, Camatte S, Lelièvre L, Daraï E, Lécuru F. Previous abdominal surgery and closed entry for gynaecological laparoscopy: a prospective study. BJOG. 2005;112:100-2.

10. Audebert AJM, Gomel V. Role of microlaparoscopy in the diagnosis of peritoneal and visceral adhesions and in the prevention of bowel injury associated with blind trocar insertion. Fertil Steril. 2000;73(3):631-5.

11. Sigel B, Golub RM, Loiacono LA, Parsons RE, Kodama I, Machi J, et al. Technique of ultrasonic detection and mapping of abdominal wall adhesions. Surg Endosc. 1991;5:161-5.

12. Kolecki RV, Golub RM, Sigel B, Machi J, Kitamura $\mathrm{H}$, Hosokawa $\mathrm{T}$, et al. Accuracy of viscera slide detection of abdominal wall adhesions by ultrasound. Surg Endosc. 1994;8:871-4. 
13. Borzellino G, Manzoni GD, Ricci F. Detection of abdominal adhesions in laparoscopic surgery. Surg Laparosc Endosc. 1998;273-6.

14. Aubé C, Pessaux P, Tuech JJ, du Plessis R, Becker P, Caron $\mathrm{C}$, et al. Detection of peritoneal adhesions using ultrasound examination for the evaluation of an innovative intraperitoneal mesh. Surg Endosc. 2004; 18:131-5.

15. Kothari SN, Fundell LJ, Lambert PJ, Mathiason MA. Use of transabdominal ultrasound to identify intraabdominal adhesions prior to laparoscopy: a prospective blinded study. Am J Surg. 2006;192:8437.

16. Larciprete G, Valli E, Meloni P, Malandrenis I. Ultrasound detection of the "sliding viscera" sign promotes safer laparoscopy. J Minim Invasive Gynecol. 2009;16(4):445-9.
17. Nezhat CH, Dun EC, Katz A, Wieser FA. Office Visceral Slide Test compared with two Perioperative Tests for predicting periumbilical adhesions. Obstetr Gynecol. 2014;123(5):1049-56.

18. Firoozabadia M, Alibakhshia A, Alaeenb H, Zand S, Nazemian R, Rahmani M. Evaluation of the diagnostic potential of transabdominal ultrasonography in detecting intra-abdominal adhesions: A double-blinded cohort study. Ann Med Surg. 2018;36(7):79-82.

Cite this article as: Rani N, Rajaram S, Chaube S, Rathi V. Preoperative ultrasonography in the evaluation of abdominal wall adhesions. Int J Reprod Contracept Obstet Gynecol 2020;9:4513-20. 